\title{
The Vicious Circle of Non-performing Assets: An introspection for Indian banks to ensure their profitability amidst COVID - 19 pandemic
}

\author{
Banajit Changkakati, Assistant Professor, Gauhati University, Guwahati, India, \\ banajitc@gauhati.ac.in \\ Upasana Sharma, Research Scholar, Gauhati University, Guwahati, India, \\ upasana.sharma92@gmail.com
}

\begin{abstract}
The non performing assets (NPAs) or bad loans, as we understand generally, have always been one of the key challenges for Indian banks and financial institutions and they have been adversely affecting the sustainability of these financial service providers. While performing the basic function of extending credit in order to earn interest income, however, it is also important for these institutions to have an efficient and effective credit risk assessment mechanism in place, so that, a proper balance between profitability and sustainability is maintained. Credit scoring models are one of the most important components of credit risk assessment mechanism and banks and financial institutions of many developed countries have developed credit scoring models based on advanced technologies. On the contrary, most of the Indian banks are still dependent on the traditional way of developing credit scoring models, which might be a deterrent against ensuring safe credit policy amidst the COVID - 19 pandemic.
\end{abstract}

Keywords - gross non-performing asset, multiple regression, net interest margin, net non performing asset, return on asset, non-performing asset, return on equity, vicious circle of non-performing asset

\section{INTRODUCTION}

One of the major functions performed by the banks is through providing loans and advances to their customers. However, while providing these kinds of services these banks run the risk of non repayment or loss of payment and these kinds of risks are termed as credit risk. In other words, credit risk is defined as the probability of default associated with repayment of the loans and advances provided to the customers of a particular bank or a financial institution.

When these loans and advances remain unpaid for a specific time period, these are termed as bad loans or non performing assets. As credit risk increase, it increases the probability of a loan turning into a bad loan or NPA and as the number of NPA increases; it adversely affects the profitability and the long term success as well as poses a threat to the sustainability of the bank. Therefore, in order to mitigate credit risk, it is vital on part of every bank to have an appropriate and robust credit risk assessment system in place without which problems like NPA can't be resolved in an effective manner. Also at a time when the Indian economy is going through a tough phase due to the spread of COVID -19, and there is tremendous pressure for revival of the Medium, Small, Micro Enterprises (MSME) sectors, this research is expected to help banks develop a defence mechanism for protection against giving loans to doubtful customers

Non-performing assets (NPAs)

As per the definition of RBI, an asset becomes nonperforming when it ceases to generate income for the bank. A non-performing asset was defined as a credit facility in respect of which the interest and/or instalment of principal has remained 'past due' for a specified period of time i.e., more than 90 days. Non-performing assets are classified into three categories based on the time period for which they remained non-performing, namely, sub standard assets, doubtful assets and loss assets.

Sub-standard Assets: A sub-standard asset was one, which has remained NPA for a period less than or equal to 18 months. In such cases, the current net worth of the borrower/ guarantor or the current market value of the security charged is not enough to ensure recovery of the dues to the banks in full.

Doubtful Assets: A doubtful asset was one, which has remained NPA for a period exceeding 18 months. A loan classified as doubtful has all the weaknesses inherent in assets that were classified as sub-standard, with the added characteristic that the weaknesses make collection or liquidation in full, - on the basis of currently known facts, 
conditions and values - highly questionable and improbable.

Loss Assets: A loss asset is one where loss has been identified by the bank or internal or external auditors or the RBI inspection but the amount has not been written off wholly. In other words, such an asset is considered uncollectible and of such little value that its continuance as a bankable asset is not warranted although there may be some salvage or recovery value.

\section{The vicious circle of NPA}

NPAs also follow a vicious circle which indicates that, a lack of a robust credit risk management system will lead to inefficient credit risk assessment and credit scoring, which in turn, will lead to faulty credit decisions and it will increase the number of bad loans or non-performing assets and again, higher NPA will lead to low profitability, liquidity and investment. The entire process is depicted by the figure below.

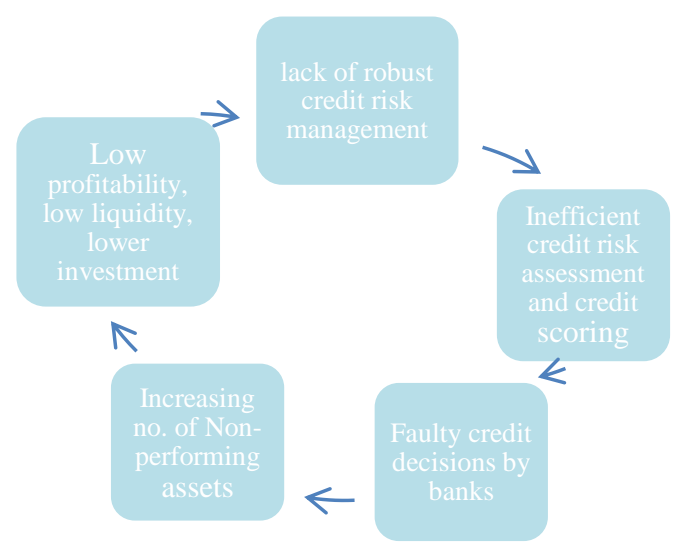

Although a number of parameters associated with profitability of banks, which get adversely affected by nonperforming assets are there; however three of them, namely Return on assets (RoA), Return on equity (RoE) and net interest margin (NIM) are considered by the researchers to be most appropriate for the current study.

\section{Credit Scoring}

Credit scoring has been one of the most important techniques used for classification of customers of a bank into defaulters and non defaulters. It is one of the widely used parameters for credit risk assessment. Credit score is a numerical value assigned to a customer on the basis of certain information such as demographic and financial information pertaining to the customer to represent the creditworthiness of the customer.

With the introduction of Basel II Accord, it has been inevitable on part of the banks to implement the most appropriate credit scoring techniques for their credit portfolios.

This paper is organized in the following manner. The first section, that is, section I, consisted of the introduction, the next section, i.e., section II consists of the review of literature; followed by section III consisting of the research methodology. Again, in section IV results and discussions are illustrated by the researchers. Section V includes conclusion followed by section VI that includes future scope of research. References are also provided at the end of the paper to help the readers in understanding the concepts related to the study.

\section{LITERATURE REVIEW}

In the context of research, credit risk assessment and Nonperforming assets has been one of the most widely studied area of research not only in India but across the globe, in the recent past and its importance have grown enormously over the years. Out of the many literatures, several important contributions made in this area have been discussed in the context of the present study.

Parab and Patil, (2018) carried out a study that aimed at assessing the influence of credit risk on the performance of public and private sector banks in India. They used correlation and panel regression models for analysis. They concluded that, the efficient and effective performance of the banking industry of a country over a period of time is an indicator of the financial stability of a nation and the extent to which banks extend credit to the public for productive purposes accelerates the process of development.

Sharifi and Akhter, (2016) carried out a study to analyze the effect of non-performing assets on the profitability of public sector banks of India. The analysis and findings of the study, showed that, non-performing assets have a negative and significant impact on the bank's financial performance. They further suggested that, public sector banks should be allowed to come up with their own measures in addressing the problem of non-performing assets.

Singh and Vashisht, (2019) in their study had taken into account the credit risk management in Indian banks with special reference to non-performing assets as it has become a critical performance area for all banks in India. They concluded the study with a note that, there was no significant difference between the public and private sector banks with respect to the NPAs and the tools and techniques used to reduce it and they also found that, the most prevalent cause for the prominence of NPA was high cost of funds in public sector banks and in private sector banks the most prevalent cause was wilful defaulters.

Bawa et al. (2019) carried out an analysis of nonperforming assets of Indian banks. This study evaluated the effect of financial ratios on bank NPAs using a comprehensive framework of 31 variables under the intermediation approach. They have used a bank's operating, liquidity, solvency, profitability, capital adequacy and business development capacity together to identify the determinants affecting NPAs in the Indian banking system. 
According to, Bekhet and Eletter, (2014) credit risk is the most critical and the biggest challenge facing banks' management as the inability to precisely determine risk adversely affects credit management. They put emphasis on evaluating both accept and reject decisions because when credit manager approves a loan, he/she risks the possibility that the customer may be unable to repay his/her obligation. Conversely, when loan is rejected, there is a risk of losing a potentially profitable customer to competitors and the risk of opportunity cost.

According to Brown and Mues, (2012), in the previous research literatures, portfolios that can be considered as very low risk, or low default portfolios(LDPs), have had little attention paid to them in particular with regards to which techniques are most appropriate for scoring them. Therefore, there was a need to conduct a study taking into account real life imbalanced credit scoring data sets. They have used both traditional as well as advanced techniques of classification in order to analyze the data sets.

As stated in Abdou et al. (2016), the development of credit scoring models for predicting and decision making in the financial sector has always been associated with the developed countries, whilst developing countries have been largely neglected. Therefore, they carried out the study to show clearly the powerful role of credit scoring models in emerging economies. In their study, they have applied sophisticated techniques for building credit scoring models and compared them with the traditional techniques.

Moradi and Rafiei (2019) put emphasis on developing a dynamic credit risk assessment model using data mining technique. Traditionally, banks have used static modelling frameworks to assess customer credit risks, however, the lack of responsiveness to the evolving economic environment rendered those models inefficient, especially in the face of concept drifts, where a portion of good customers fall into default (i.e., become bad customers). They introduced a new dynamic model that could accommodate changing uncertain factors as well as the more stable certain factors used in static models.

\section{RESEARCH METHODOLOGY}

Research methodology adopted for the current study can be explained as a two stage approach. At the first stage, the researchers used exploratory research to understand the current credit risk assessment mechanism of banks and the current trend in non-performing assets of Indian banks. The second stage is followed by a quantitative analysis carried out to analyze the relationship between non-performing assets and various profitability parameters of Scheduled commercial banks (SCBs).

\section{A. Objectives of the study}

i. To study the trend in non-performing assets and performance of Indian banks with respect to the same. ii. To understand the current credit risk assessment mechanism of Indian banks from the existing literature.

iii. To analyze the relationship between nonperforming assets and different parameters of performance of Indian banks.

\section{B. Research hypotheses}

\section{The first research hypothesis is as follows-}

H01: There is no significant effect of NPA on RoE.

\section{Sub hypotheses:}

H01.1: there is no significant impact of GNPA on RoE. H01.2: there is no significant impact of NNPA on RoE. The second hypothesis is as follows-

H02: There is no significant effect of NPA on RoA.

\section{Sub hypotheses:}

H02.1: there is no significant impact of GNPA on RoA. H02.2: there is no significant impact of NNPA on RoA. The third hypothesis is as follows-

H03: There is no significant effect of NPA on NIM.

\section{Sub hypotheses:}

H03.1: There is no significant impact of GNPA on NIM. H03.2: There is no significant impact of NNPA on NIM.

\section{Statistical technique used in the current study}

Multiple regression is one of the widely used statistical techniques for analyzing cause-effect relationship that may exist between dependent variable and independent variables considered in a particular study. The analysis also helps identifying the independent variables that are most relevant in predicting the values of a dependent variable. It can simultaneously deal with both quantitative and categorical variables.

The general form of a multiple regression model is given as

$$
y=\beta_{\mathrm{o}}+\beta_{1} x_{1}+\beta_{2} x_{2}+\cdots \cdots \cdots \cdots \cdots+\beta_{\mathrm{p}} x_{\mathrm{p}}+\epsilon
$$

Where, $y$ is the dependent variable, $x_{1}, x_{2} \cdots \cdots \cdots \cdots, x_{\mathrm{p}}$ are the independent variables, $\beta_{0}$ is the intercept , $\beta_{1}$, $\beta_{2}, \ldots \ldots \ldots \ldots \ldots, \beta_{\mathrm{p}}$ are partial regression coefficients and $\epsilon$ is the error term or the residual term.

One of the basic assumptions of multiple regression model is that the mean or expected value of $\epsilon$ is zero. A consequence of this assumption is that the mean or expected value of $y$, denoted $E(y)$, is equal to $\beta_{0}+\beta_{1} x_{1}+$ $\beta_{2} x_{2}+\cdots \cdots \cdots \cdots \cdots+\beta_{\mathrm{p}} x_{\mathrm{p}}$ The equation that describes how mean value of $\mathrm{y}$ is related to $x_{1}, x_{2} \cdots \cdots \cdots \cdots, x_{\mathrm{p}}$ is called the multiple regression equation.

\section{Multiple Regression Equation:}

$\mathrm{E}(\mathrm{y})=\beta_{\mathrm{o}}+\beta_{1} x_{1}+\beta_{2} x_{2}+\cdots \cdots \cdots \cdots \cdots+\beta_{\mathrm{p}} x_{\mathrm{p}}$

The estimated multiple regression equation is given by 
$\hat{\mathrm{y}}=\alpha+\mathrm{b}_{1} x_{1}+\mathrm{b}_{2} x_{2}+\cdots \cdots \cdots \cdots \cdots+\mathrm{b}_{\mathrm{p}} x_{\mathrm{p}}$

where $\hat{y}$ is the predicted value of the dependent variable $y$, $\alpha$ is the intercept and $\beta$ s are the partial regression coefficients.

\section{Statistics associated with Multiple Regression:}

Multiple R: the multiple correlation co efficient, $\mathrm{R}$, is defined as the simple correlation co efficient, $r$, between the observed value of $y$ (dependent variable) and the predicted value of $y$.

Coefficient of multiple determination: The strength of association in multiple regression is measured by the square of the multiple correlation coefficient, $\mathrm{R}^{2}$, which is also called the co efficient of multiple determination.

Adjusted $\mathbf{R}^{2}: \mathrm{R}^{2}$, coefficient of multiple determination, is adjusted for the number of independent variables and the sample size to account for diminishing returns. After the first few variables, the additional variables don't make much contribution.

F- test: The F-test is used to test the null hypothesis that the coefficient of multiple determination in the population is zero. The null hypothesis to be tested is

Ho: $\beta_{1}=\beta_{2}=\beta_{3}=\ldots \ldots \ldots=\beta_{p}=0$.

The test statistic has an $\mathrm{F}$ distribution with $\mathrm{p}$ and (n-p-1) degrees of freedom.

t-statistic: A t-statistic can be used to test the null hypothesis that no linear relationship exists between the dependent and independent variable.

Standard error: The standard deviation of the regression coefficient is called the standard error.

Residual: A residual is the difference between the observed value of the dependent variable and the predicted value of the dependent variable.

p-value: The p-value is the probability of rejecting the null hypothesis.

\section{Source of data}

For the current study, secondary data pertaining to a period of 10 years, from 2009-2019 have been collected from annual reports of banks published by Reserve bank of India.

\section{RESULTS AND DISCUSSIONS}

For analysis of the data multiple regression technique is used and the analysis is performed using Microsoft excel.

The general form of a multiple regression model is:

$$
y=\beta_{\mathrm{o}}+\beta_{1} x_{1}+\beta_{2} x_{2}+\cdots \cdots \cdots \cdots \cdots+\beta_{\mathrm{p}} x_{\mathrm{p}}+\epsilon
$$

For data analysis the following parameters are considered:

\begin{tabular}{|l|l|l|l|l|l|}
\hline Year & $\begin{array}{l}\text { RoA of all } \\
\mathrm{SCBs}(\%)\end{array}$ & $\begin{array}{l}\text { RoE of all } \\
\mathrm{SCBs}(\%)\end{array}$ & $\begin{array}{l}\text { Net } \\
\text { interest } \\
\text { margin } \\
(\%)\end{array}$ & $\begin{array}{l}\text { GNPA (as } \\
\% \text { of gross } \\
\text { advances) }\end{array}$ & $\begin{array}{l}\text { NNPA (as } \\
\% \text { of net } \\
\text { advances) }\end{array}$ \\
\hline $2009-10$ & 1.05 & 14.31 & 2.54 & 2.5 & 1.12 \\
\hline $2010-11$ & 1.1 & 14.96 & 2.91 & 2.4 & 1 \\
\hline $2011-12$ & 1.08 & 14.6 & 2.9 & 2.9 & 1.4 \\
\hline $2012-13$ & 1.03 & 13.84 & 2.79 & 3.2 & 1.7 \\
\hline $2013-14$ & 0.81 & 10.68 & 2.7 & 3.8 & 2.1 \\
\hline $2014-15$ & 0.81 & 10.42 & 2.64 & 4.3 & 2.4 \\
\hline $2015-16$ & 0.31 & 3.59 & 2.6 & 7.5 & 4.4 \\
\hline $2016-17$ & 0.35 & 4.16 & 2.49 & 9.3 & 5.3 \\
\hline $2017-18$ & -0.2 & -2.8 & 2.5 & 11.2 & 6 \\
\hline $2018-19$ & -0.09 & -1.85 & 2.7 & 9.1 & 3.7 \\
\hline
\end{tabular}

Source: RBI annual reports on trend and progress of Indian banking. Compiled by the researchers.

\section{First hypothesis and interpretations}

For the first hypothesis, i.e., H01, the results of the analysis can be summarized as follows:

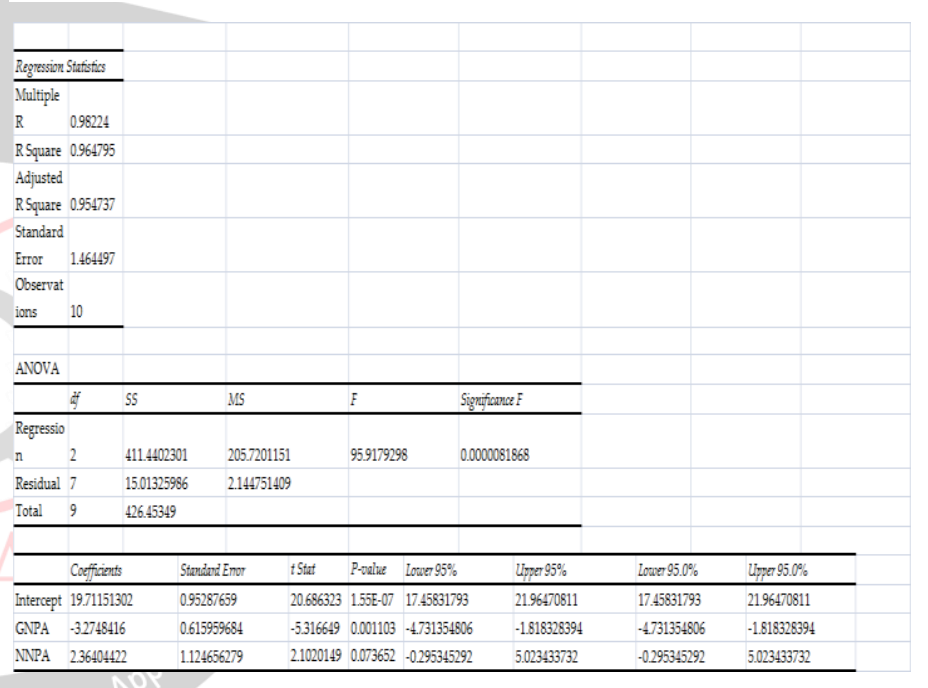

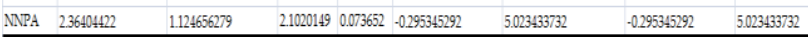

The value of $\mathrm{R}$ square obtained in the analysis of the first hypothesis, is $0.965(96.5 \%)$. The value of $\mathrm{R}$ square always lies between 0 and 1 , and as it approaches 1 , it can be interpreted that the proportion of variability in the dependent variable can be explained by the estimated multiple regression equation. In the current study the value of R square is approaching the higher range and therefore, it can be interpreted that, the independent variables considered under the study are highly significant enough to explain the variability in the dependent variable.

The value of Adjusted R square is $0.955(96 \%)$. This value indicated that, all the independent variables are equally helpful in predicting the variation in the dependent variable. Individual effects of the independent variables are highly significant.

The calculated value of the $F$ statistic for the first hypothesis is $\mathrm{F}=95.91$, with 2 (numerator) and 7 (denominator) degrees of freedom. The calculated $\mathrm{F}$ statistic exceeds the tabulated or critical value of $\mathrm{F}$ statistic 
which is 4.74 , therefore, it can be interpreted that the relationship between dependent and independent variable is significant. Hence, we can reject the null Hypothesis in Hypothesis 1 which stated that, the regression relationship between dependent and the independent variables is not significant. Symbolically,

Ho: $\beta_{1}=\beta_{2}=\beta_{3}=\ldots \ldots \ldots .=\beta_{p} \neq 0$

The p-value associated with GNPA ( $\mathrm{p}=.0001)$ for H01.1, is significant at $5 \%$ level of significance as $\mathrm{p}<.05$ and the $\mathrm{p}$ value associated with NNPA $(\mathrm{p}=0.07)$ for $\mathrm{H} 01.2$, is significant at $10 \%$ level of significance as $\mathrm{p}<.10$. Therefore, both the hypotheses, are rejected and it can be interpreted that, both GNPA and NNPA have significant effects on RoE.

\section{Second hypothesis and interpretations}

For the second hypothesis, i.e., H02:, the results are as follows:

\begin{tabular}{|c|c|c|c|c|c|c|c|c|}
\hline SUMMARY OUTPU & & & & & & & & \\
\hline \multicolumn{9}{|c|}{ Regression Statistics } \\
\hline Muttiple R & 0.9832656 & & & & & & & \\
\hline RSquare & 0.9668112 & & & & & & & \\
\hline Adjusted RSquare & 0.9573287 & & & & & & & \\
\hline Standard Error & 0.1024197 & & & & & & & \\
\hline Obsenations & 10 & & & & & & & \\
\hline \multicolumn{9}{|l|}{ ANOVA } \\
\hline & of & 55 & MS & $F$ & Signiffconce F & & & \\
\hline Regression & & 2.1390215 & 1.069511 & 101.9573513 & $6.666: 06$ & & & \\
\hline Residual & & 0.0734285 & 0.01049 & & & & & \\
\hline \multirow[t]{2}{*}{ Total } & & 2.21245 & & & & & & \\
\hline & Coefficients it & itondord Errol & tstat & P.value & Lower 95\% & Upper 95\% lo & Lower 95.06 4 & Upper 95.0\% \\
\hline Intercept & 1.4553905 & 0.0666395 & 21.83977 & 1.07507 & 1.2978132 & 1.612968 & 1.297813 & 1.612968 \\
\hline GNPA & -0.2397373 & 0.0430772 & .5565299 & 0.000846188 & 0.3415986 & 0.13788 & .0 .3416 & 0.13788 \\
\hline NNPA & 0.1775182 & 0.0786529 & 2.256983 & 0.058591501 & .000846628 & 0.363503 & .000847 & 0.363503 \\
\hline
\end{tabular}

The value of $\mathrm{R}$ square obtained in the analysis of the second hypothesis, is $0.967(96.7 \%)$. Since, the value of $\mathrm{R}$ square is approaching the higher range, therefore, it can be interpreted that, the independent variables considered under the study are highly significant enough to explain the variability in the dependent variable.

Again, the value of Adjusted R square is 0.957(95.7\%). This value indicated that, all the independent variables are equally helpful in predicting the variation in the dependent variable. Individual effects of the independent variables are highly significant.

The calculated value of the $F$ statistic for the first hypothesis is $\mathrm{F}=101.95$, with 2 (numerator) and 7 (denominator) degrees of freedom. The calculated $\mathrm{F}$ statistic exceeds the tabulated or critical value of $\mathrm{F}$ statistic which is 4.74 , therefore, it can be interpreted that the relationship between dependent and independent variable is significant. Hence, we can reject the null Hypothesis in Hypothesis 2, that the regression relationship between dependent and the independent variables is not significant. Symbolically,

$$
\text { Ho: } \beta_{1}=\beta_{2}=\beta_{3}=\ldots \ldots \ldots=\beta_{p} \neq 0
$$

Again the p-values associated with GNPA $(\mathrm{p}=.0008)$ for H02.1 and the $p$-value associated with NNPA $(p=0.05)$ for $\mathrm{H} 02.2$, are significant at $5 \%$ level of significance as $\mathrm{p}<.05$. Therefore, both the hypotheses, are rejected and it can be interpreted that, both GNPA and NNPA have significant effects on RoA.

\section{Third hypothesis and interpretations}

For the third hypothesis, i.e., H03, the results are as follows: SUMMARV OUTPUT

\begin{tabular}{|c|c|c|c|c|c|c|c|c|}
\hline \multicolumn{9}{|l|}{ Regression Statistics } \\
\hline Muttiple R & 0.7278924 & & & & & & & \\
\hline R Square & 0.5298273 & & & & & & & \\
\hline Adjusted R Square & 0.3954923 & & & & & & & \\
\hline Standard Error & 0.1188246 & & & & & & & \\
\hline Observations & 10 & & & & & & & \\
\hline \multicolumn{9}{|l|}{ ANOVA } \\
\hline & $d f$ & $s s$ & MS & $F$ & Significance F & & & \\
\hline Regression & 2 & 0.111375 & 0.055688 & 3.944073892 & 0.07126902 & & & \\
\hline Residual & 7 & 0.098835 & 0.014119 & & & & & \\
\hline \multirow[t]{2}{*}{ Total } & 9 & 0.21021 & & & & & & \\
\hline & Coefficients & $\begin{array}{l}\text { Standard } \\
\text { Error }\end{array}$ & tStat & P-value & Lower 95\% & Upper 95\% & $\begin{array}{l}\text { Lower } \\
90.0 \% 5\end{array}$ & $\begin{array}{l}\text { Upper } \\
\text { 90.0\%\% }\end{array}$ \\
\hline Intercept & 2.8350175 & 0.0773134 & 36.66918 & $2.92 \mathrm{E}-09$ & 2.65220044 & 3.0178345 & 2.6885413 & 2.9814937 \\
\hline GNPA (s of a avances) & 0.0335872 & 0.049977 & 0.672052 & 0.523105132 & -0.08458966 & 0.151764 & -0.0610982 & 0.1282725 \\
\hline NNPA(Sof advances) & -0.1190856 & 0.091251 & -1.305033 & 0.23314098 & -0.33485997 & 0.0966887 & -0.2919678 & 0.0537966 \\
\hline
\end{tabular}

The value of $\mathrm{R}$ square obtained in the analysis of the third hypothesis, is $0.728(72.8 \%)$. In this case, it can be interpreted that, the independent variables considered under the study are just significant but not highly significant to explain the variability in the dependent variable.

The value of Adjusted R square is $0.395(39.5 \%)$. This value indicated that, all the independent variables are not equally helpful in predicting the variation in the dependent variable. Individual effects of the independent variables are not significant.

The calculated value of the $F$ statistic for the third hypothesis is $\mathrm{F}=3.944$, with 2 (numerator) and 7 (denominator) degrees of freedom. The calculated $\mathrm{F}$ statistic is less than the tabulated or critical value of $F$ statistic which is 4.74 , therefore, it can be interpreted that the relationship between dependent and independent variable is not significant enough to reject the null hypothesis $\mathrm{H} 03$.

Symbolically,

Ho: $\beta_{1}=\beta_{2}=\beta_{3}=\ldots \ldots \ldots .=\beta_{p}=0$

Again the $p$-values associated with GNPA $(p=0.52)$ for H03.1 and NNPA ( $\mathrm{p}=0.23$ ) for H03.2, are not significant as $\mathrm{p}>.05$ at $5 \%$ level of significance. Therefore, both the null 
hypotheses, can't be rejected and it can be interpreted that, both GNPA and NNPA have no significant effects on NIM.

\section{CONCLUSION}

NPAs have highly significant impact on the most important parameters of profitability of a bank and therefore, measures must be taken to lower the NPAs as much as possible and banks must develop efficient mechanisms to eradicate the adverse impact of these menaces. Credit risk assessment has always been the most critical and important factor for assessing the creditworthiness of any customer. The inability to precisely determine risk adversely affects the credit management. This in turn leads to bad credit decision and eventually contributes to the pool of NPAs. Therefore it is very important on part of the bank to have an appropriate credit risk assessment system in place for maintaining profitability and ensuring long term survival of a bank. It was also found in the study, that, certain factors are more severely affected by non-performing assets as compared to certain others.

Lastly this research paper is focused on the need to reduce losses to the Indian banks as they gear up amidst mounting pressure to revive the MSME sector in a bid to keep the Indian economy healthy amidst the COVID - 19 pandemic. Reduction of NPAs will be the key to sustenance of the Indian economy, as it is expected that the world is going to go through a period of recession. Those economies that emerge faster will have a winning edge over other countries. This is one grey area that India as a country can be better geared up to tackle compared to other countries.

Hence, this paper is a humble step in highlighting how NPAs can make the foundation of a country weak and how timely intervention can help an economy be prepared for a faster recover from a global recession compared to its global counterparts and competitors.

\section{FUTURE SCOPE FOR RESEARCH}

Though areas like non-performing assets and credit risk assessments have been widely studied across countries, yet there is scope for further research. These challenges have been persistent for a very long time and they continue to be amongst the biggest challenges facing Indian banking sector. Therefore, in future work, efforts must be directed towards understanding these issues in light of the current trend, keeping in mind the dynamics of NPA and credit risk assessment.

In most of the previous studies, NPA and credit risk assessment have been studied separately as two different subject matters. However, further research can be directed towards analyzing their combined effects. Again, in most of the literatures reviewed for the current study, it was found that emphasis was given on developing appropriate credit scoring models for credit risk assessment using data mining techniques, specifically in the developed countries.
However, in Indian context, only a few models have been developed using advanced techniques. Therefore, further studies can be directed towards applying advanced techniques for developing credit scoring models, so that, challenges like, NPA can be handled in an efficient and effective manner.

Conflict of Interest: No conflict of interest was reported by the authors.

\section{REFERENCES}

[1] Abdou, H.A., Tsfack, M.D.D., Ntim, C.G., Baker R.D. (2016). Predicting creditworthiness in retail banking with limited scoring data. Knowledge Based Systems, Vol. 103 pp. 89-103.

[2] Ala'raj, M., Abbod, M.F. (2016). Classifiers consensus system approach for credit scoring. Knowledge Based Systems, Vol. 104, pp. 89-105.

[3] Bao,W., Lianju, N., Yue, Kong. (2019) Integration of unsupervised and supervised machine learning algorithms for credit risk assessment. Expert Systems With Applications, Vol. 128, pp. 301-315.

[4] Bawa,J.K., Goyal, V., Mitra, S.K. and Basu,S.(2019) An analysis of NPAs of Indian Banks: Using a comprehensive framework of 31 financial ratios. IIMB Management Review,(31), page no. 51-62.

[5] Bekhet, H.A., Eletter,S.F.K. (2014). Credit risk assessment model for Jordanian commercial banks: Neural Scoring Approach. Review of Development Finance, Vol. 4 pp. 20-28.

[6] Benhayoun, N., Chairi, I., Gonnouni, A.E., Lyhyaoui, A. (2013). Financial Intelligence in Prediction of Firm's Creditworthiness Risk: Evidence from Support Vector Machine Approach. Procedia Economics and Finance, Vol.5, pp.103-112.

[7] Brown, I., Mues, C. (2012). An experimental comparison of classification algorithms for imbalanced credit scoring data sets. Expert Systems with Applications, Vol.39, Issue 3, pp. 3446-3453.

[8] Butaru, F., Chen, Q., Clark, B., Das, S., Lo, A.W., Siddique, A. (2016). Risk and risk management in the credit card industry. Journal of Banking and Finance, Vol. 72, pp. 218-239.

[9] Chen, H., Xiang, Y. (2017). The Study of Credit Scoring Model Based on Group Lasso. Procedia Computer Science, Vol. 122, pp. 677-684.

[10]Eletter, S.F., Yaseen, S. G., \& Elrefae, G.A. (2010). Neuro- Based Artificial Intelligence Model for Loan Decisions. American Journal of Economics and Business Administration, 2(1), 27-34. 
[11] Guegan, G., Hassani, B. (2018). Regulatory learning: How to supervise machine learning models? An application to credit scoring. The Journal of Finance and Data Science 4, 157-171.

[12] Guo, Y., Liang, C. (2016). Blockchain application and outlook in the banking industry. Financial Innovation , pp. 1-12.

[13] Moradi, S., \& Rafiei, F.M. (2019). A dynamic credit risk assessment model with data mining techniques: evidence from Iranian banks. Financial innovation, pp.1-27.

[14] Moray, R. (2017). Indian Banks and Credit Scoring Models. An Empirical Study. Asian Journal of Research in Banking and Finance, Vol.7, No. 7, pp. 165-180.

[15] Nazari, M., Alidadi, M. (2013). Measuring Credit Risk of Bank Customers Using Artificial Neural Network. Journal of Management Research, Vol. 5, No. 2, pp. 17-27.

[16] Parab, C.R., Patil, M.R.(2018) Credit risk and Public and Private Banks' Performance in India: A Panel Approach. International Refereed Research Journal, Vol. IX, Issue 2, page no. 34-42.

[17] Purohit, S.U., Mahadevan,V., \& Kulkarni, A.N. (2012). Credit Evaluation Model of Loan Proposals for Indian Banks. International Journal of Modeling and Optimization, Vol. 2, No. 4, pp. 529-534.

[18] Sharifi,O., Akhter, J.(2016) Effect of NPA on the Profitability of Public Sector Banks of India. International Journal of Engineering and ManagementResearch, Vol. 6, Issue 5, page no. 383388.

[19] Singh, H., Vashisht, A.(2019) Credit Risk Management in Banking Sector: A Comparison of NPAs of Public and Private Sector Banks. International Journal of Research in Advent Technology, Vol.7, No.5, page no. 442-447.

[20] Sudhamathy, G. (2016). Credit Risk Analysis and Prediction Modelling of Bank Loans using R. International Journal of Engineering and Technology, Vol. 8 , No. 5.

[21] Vanneschi, L., Horn, D. M., Castelli, M., Popovic, A. (2018). An artificial intelligence system for predicting customer default in e-commerce. Expert Systems With Applications, Vol. 104, pp. 1-21.

[22]RBI Annual Reports. Retrieved from https://www.rbi.org.in/ Scripts/AnnualReportMain Display .aspx

[23] RBI report on trend and progress of Banking in India.
[24] Retrieved from https://www.rbi.org.in/Scripts/AnnualPublications. aspx?head=Trend $\% 20$ and $\% 20$ Progress $\% 20$ of $\% 20 \mathrm{Bank}$ ing $\% 20$ in $\% 20$ India.

[25]RBI Publications. Retrieved from https:/www.rbi.org.in/Scrip ts/ Publications View.aspx? id= 18523

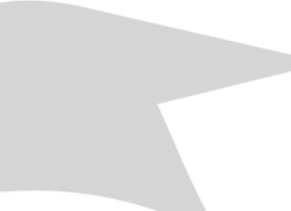

\author{
(1)
}

